\title{
Identity and distribution of weedy Pedicularis kansuensis Maxim. (Orobanchaceae) in Tianshan Mountains of Xinjiang: morphological, anatomical and molecular evidence
}

\author{
SUI Xiaolin ${ }^{1}$, Patrick KUSS ${ }^{2}$, LI Wenjun ${ }^{3,4}$, YANG Meiqing ${ }^{5}$, GUAN Kaiyun ${ }^{1,3}$, LI Airong ${ }^{1 *}$ \\ ${ }^{1}$ Yunnan Key Laboratory for Research and Development of Wild Plant Resources, Kunming Institute of Botany, Chinese \\ Academy of Sciences, Kunming 650201, China; \\ ${ }^{2}$ Institute of Systematic Botany, University of Zürich, Zürich 8008, Switzerland; \\ ${ }^{3}$ Key Laboratory of Biogeography and Bioresource in Arid Land, Xinjiang Institute of Ecology and Geography, Chinese \\ Academy of Sciences, Urumqi 830011, China; \\ ${ }^{4}$ University of Chinese Academy of Sciences, Beijing 100049, China; \\ ${ }^{5}$ World Agroforestry Centre, East and Central Asia Region, Kunming 650201, China
}

\begin{abstract}
Weedy plants affect the biodiversity and ecosystem function as well as the crop and fodder plant production. However, adequate management requires detailed knowledge of the taxonomic identity of these plants. Here, we focused on a hemiparasitic Pedicularis species (Orobanchaceae), which occurs at high densities and results in significant biomass reductions in forage grasses in Bayanbulak Grassland of Xinjiang. The identity of this target species is not clear, with conflicting reports in publications and in herbarium collections. Hence, clear and management-relevant information on demography and reproductive ecology is difficult to be obtained from the literature. Therefore, we analyzed field and archival materials collected from Xinjiang in order to clarify the identity and distribution of the target species. Morphological analyses suggested that the populations at Bayanbulak Grassland should be Pedicularis kansuensis Maxim. rather than $P$. verticillata $L$. which has been accepted in the available literature. Phylogenetic analysis with a combination of three barcodes (matK, rbcL and $r n H-p s b A$ ) uniting a clade of $P$. kansuensis and individuals from Bayanbulak Grassland populations with 100\% bootstrap support, confirmed the target species to be $P$. kansuensis. Anatomical investigations and field observations showed that the target species is an annual or biennial herb, which also fits with the life cycle as $P$. kansuensis. Based on archive material and field observations, we verified that the distribution of $P$. kansuensis is mainly concentrated in the Tianshan Mountains of Xinjiang.
\end{abstract}

Keywords: DNA barcode; herb-chronology; morphological characters; root hemiparasite

Citation: SUI Xiaolin, Patrick KUSS, LI Wenjun, YANG Meiqing, GUAN Kaiyun, LI Airong. 2016. Identity and distribution of weedy Pedicularis kansuensis Maxim. (Orobanchaceae) in Tianshan Mountains of Xinjiang: morphological, anatomical and molecular evidence. Journal of Arid Land, 8(3): 453-461. doi: 10.1007/s40333-016-0004-0

Hemiparasitic plants retain photosynthetic capability, but still extract nutrients and water from their host plants via an anatomical structure known as a haustorium, often resulting in significant biomass reduction in their hosts (Irving and Cameron, 2009). Furthermore, they can alter the

\footnotetext{
*Corresponding author: Li Airong (E-mail: airongli@mail.kib.ac.cn)

The first and third authors contribute equally to this article.

Received 2015-07-29; revised 2015-12-14; accepted 2015-12-31

(C) Xinjiang Institute of Ecology and Geography, Chinese Academy of Sciences, Science Press and Springer-Verlag Berlin Heidelberg 2016
} 
competitive balance between host and non-host species and subsequently change plant community structure and diversity of the ecosystems where they inhabit (Davies et al., 1997; Cameron et al., 2009). Hence, hemiparasitic plants are regarded as key species in both agricultural and semi-natural communities (Phoenix and Press, 2005). In some regions, such as Africa, hemiparasitic weeds (e.g. Striga spp.) cause severe damage to crop productivity each year (Cissoko et al., 2011; Parker, 2012). In China, forage crop yield loss caused by hemiparasitic weeds is a serious issue, and several root hemiparasitic Pedicularis (Orobanchaceae) species result in rapid expansion and severe damage to grassland productivity on a large scale in the past decade (Song, 2006; Bao and Wang, 2011). Most notable is the spatial expansion of a whorl-leaved purple flowering Pedicularis species (Fig. 1) in the Bayanbulak Grassland of Xinjiang Uygur autonomous region, northwestern China.
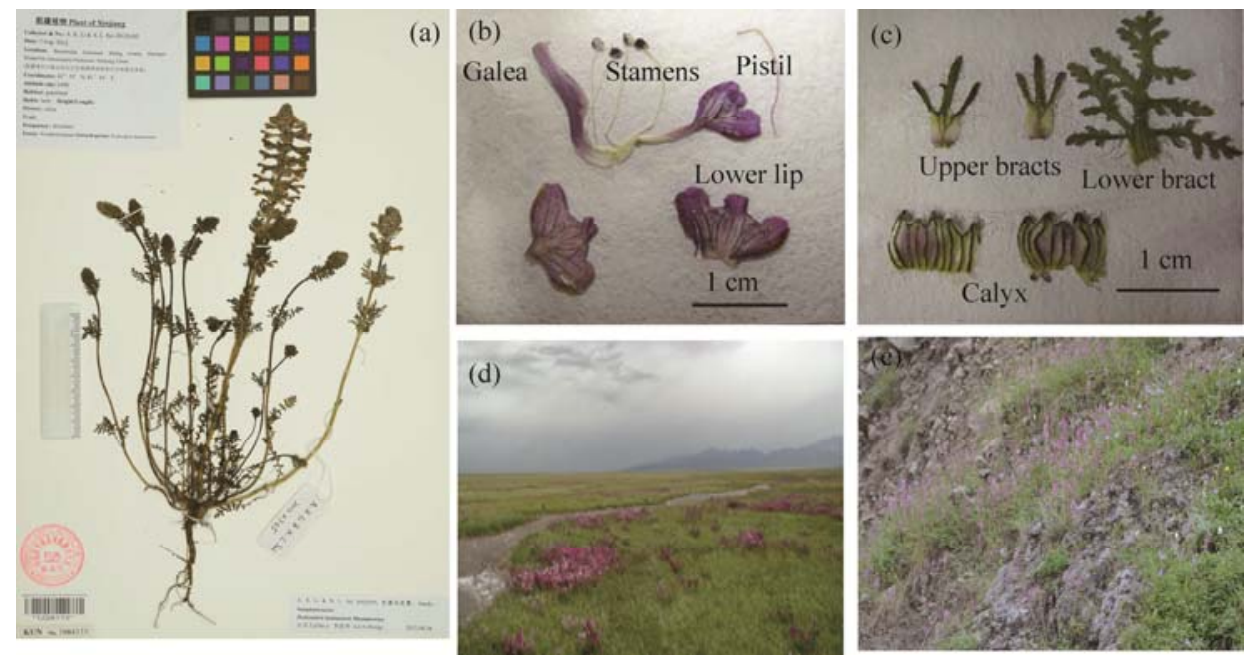

Fig. 1 Habitat, specimen and morphological characters of the Pedicularis species in Bayanbulak Grassland. (a), herbarium specimen; (b), corolla with galea and lower lip, stamens and pistil; (c), upper/lower bracts and calyx; (d) and (e), typical habitats (Photographed by SUI Xiaolin and LI Wenjun).

Bayanbulak Grassland, located in the Tianshan Mountains at a mean altitude of 2,500 $\mathrm{m}$, is the second largest grassland $\left(2.3 \times 10^{4} \mathrm{~km}^{2}\right)$ in China, and also an ecologically and economically important region of Xinjiang (Williams, 2010). The rapid spatial expansion of a whorl-leaved purple flowering Pedicularis species has caused great loss of herbage yield, threatening the local livestock industry (Liu et al., 2008; Wang et al., 2009). Hence, effective and sustainable control strategies are urgently required.

The Pedicularis species rapidly spreading within and around Bayanbulak Grassland has previously been identified as P. verticillata L. (Liu et al., 2008; Wang et al., 2009). However, based on our field observations, we considered that this species was misidentified. It has a purplish corolla with beakless galea and stem leaves in whorls of four, conforming to the descriptions for $P$. verticillata. However, the long inflorescences (up to $30 \mathrm{~cm}$ or even longer) that are often interrupted in the lower parts, three-palmate bracts in the upper parts of the stem, and obliquely ovoid capsules all suggest that this species is not $P$. verticillata, but more likely to be its closely related sister species $P$. kansuensis Maxim. This species germinates in May and flowers in late summer or the following summer, then sets seeds and dies. It is, therefore, an annual or biennial species, and not a perennial as $P$. verticillata. In addition, the high population densities found in the Tianshan Mountains do not correspond to the patterns known for the perennial $P$. verticillata from other subalpine, alpine or arctic areas throughout its distribution range in the northern hemisphere (based on personal observation). Similar high population densities are, by contrast, known for annual or biennial Asian Pedicularis species such as $P$. gracilis Wall. ex Benth., P. kansuensis Maxim., P. mollis Wall. ex Prain, P. longiflora Klotzsch and $P$. punctata Decne (personal observation). Elucidating the life cycle of the Pedicularis species is of special importance as planning and successful implementation of control measures 
depending on the information of its characters (Caswell, 2001; Silvertown and Charlesworth, 2001). Additionally, effective management regimes may already exist for the taxa with similar life cycle. In this context, the large body of literature on other problematic annual hemiparasites from Eurasia, e.g. Rhinanthus spp., had been reported (Magda et al., 2004; Bullock and Pywell, 2005; Ameloot et al., 2006; Cameron et al., 2009; Hautier et al., 2010).

In the present study, we aimed to clarify the identity of the Pedicularis species using a combination of morphological, anatomical and genetic approaches. Working with the available archival materials, we also aimed to assess the distribution range of this taxon in Xinjiang. This investigation focuses on quantifying the impact of hemi-parasites on plant community and provides information for control measures of this weedy plant.

\section{Materials and methods}

\subsection{Study area and sampling}

Field observations and sampling of the target species were conducted in Bayanbulak Grassland and surrounding areas located in the Tianshan Mountains, Xinjiang, Northwest China $\left(42^{\circ} 45^{\prime}-43^{\circ} 00^{\prime} \mathrm{N}, 83^{\circ} 40^{\prime}-87^{\circ} 15^{\prime} \mathrm{E}\right)$. Bayanbulak Grassland is characterized by an alpine climate in the temperate zonal continent with an annual precipitation around $270 \mathrm{~mm}$ and annual average temperature of $-4.8^{\circ} \mathrm{C}$ (Guan, 2007). Large areas are composed of alluvial deposits with a loess layer. Soils are generally thin and prone to erosion. These factors make Bayanbulak Grassland to be an ecologically fragile area in the northwestern region of China (Guan, 2007). The area, which is severely affected by the whorl-leaved purple flowering Pedicularis species (the target species) had reached $2.3 \times 10^{4} \mathrm{hm}^{2}$ since 2006 and had been spreading at an estimated $0.3 \times 10^{4} \mathrm{hm}^{2} /$ a (Song, 2006; Liu et al., 2008).

Morphological characters of more than one hundred individual plants collected from the infested areas were recorded. Among these plants, seven (coded as X01 to X07; see Table 1 for detailed information) were randomly chosen for molecular analysis. The plants were collected from voucher specimens after removal of fresh leaves (2-3/plant). Additional fresh leaves of allied species belonging to series Verticillatae (Tsoong, 1963) were collected from the Tianshan Mountains, Xinjiang of China (C01-C02: P. anthemifolia), Qinghai of China (K01: P. kansuensis) and Romania (L01: P. verticillata). All fresh leaves were dried immediately in silica gel for later use in molecular analyses. Detailed information about the vouchers is given in Table 1 . Voucher specimens used for obtaining morphological and molecular data were archived at the herbarium of the Kunming Institute of Botany, Chinese Academy of Sciences (KUN; Table 1).

\subsection{Archival materials}

We collected the specimens of the target Pedicularis and the information of the geography and ecology from the following herbaria: Xinjiang University (XJU), Xinjiang Agricultural University (XJA), Xinjiang Institute of Ecology and Geography (XJBI) of Chinese Academy of Sciences (CAS), Institute of Botany of CAS (PE) and Kunming Institute of Botany of CAS (KUN) (for specimen details see Table 2).

\subsection{Morphological and anatomical comparison}

Fresh and archival material was compared with relevant descriptions in the book of "Flora Xinjiangensis" (Yang et al., 1998; Pan and Nurbay, 2004) and other references in surrounding areas (Vvedensky, 1951; Pavlov, 1965; Grubov et al., 2002; Kosachev, 2010). The original descriptions (known as protologues) of relevant species (personal collection of type specimens), i.e. $P$. anthemifolia, P. futtereri, P. glabrescens, P. goniantha, $P$. kansuensis, $P$. szetschuanica var. longispicata, $P$. verticillata. $P$. verticillata var. chinensis were also included for comparison.

Growth rings in Pedicularis were determined by anatomical experiment of 3-5 tap roots taken from plants that were in flower at each of the four representative sampling sites (Table 1), randomly chosen and sectioned using method as described by Schweingruber and Poschlod (2005). The growth increments were revealed through step-wise bleaching and dyeing of microtome-cut root cross sections and subsequent observation under a dissecting microscope. 


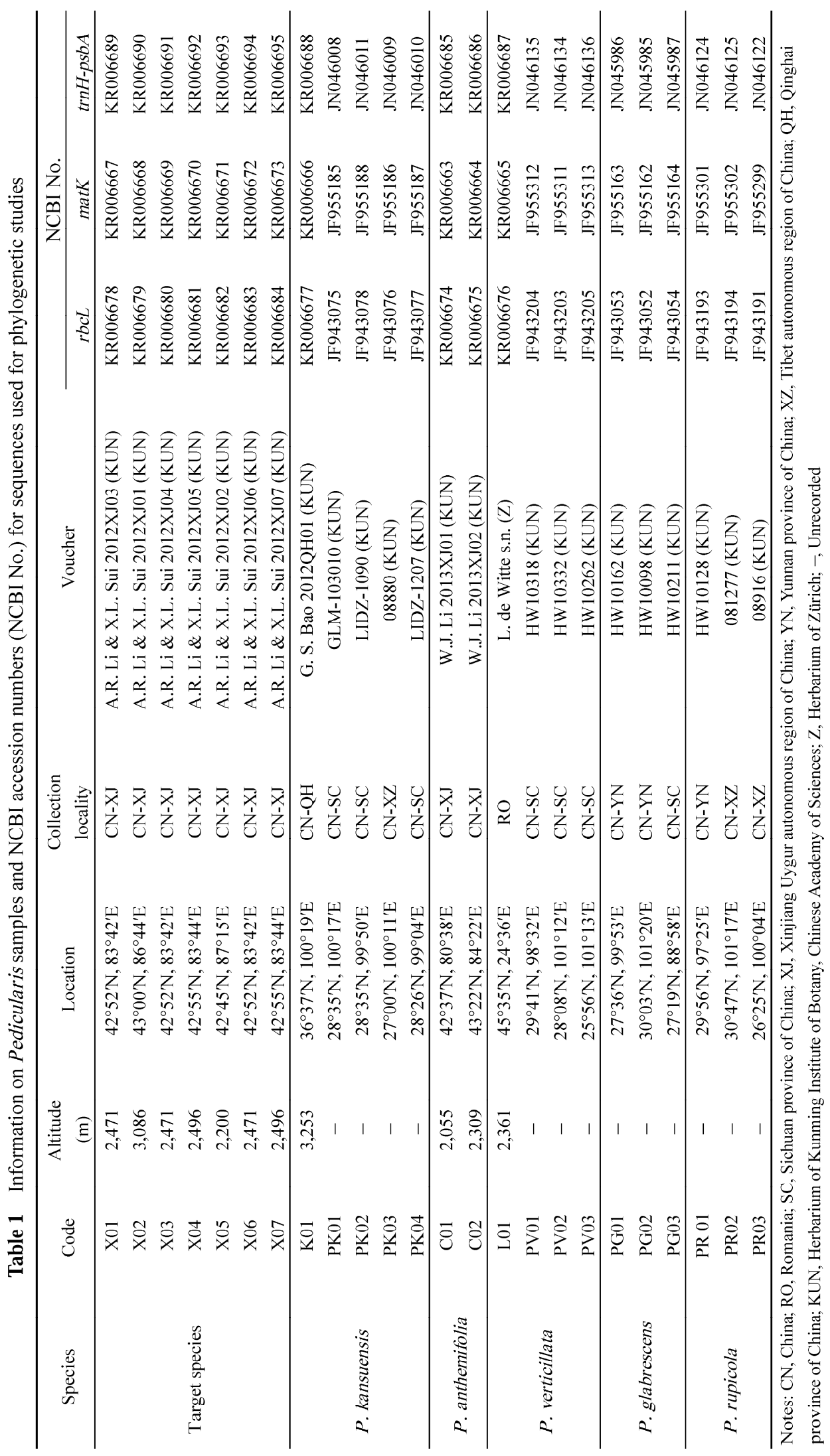


Table 2 Available archival information of the Pedicularis species

\begin{tabular}{cccccc}
\hline Herbarium & Voucher & Year & Location & $\begin{array}{c}\text { Altitude } \\
(\mathrm{m})\end{array}$ & Original identification \\
\hline XJA & X.W. Li \& J.S. Li 83-087 & 1983 & Yiwu county (XJ) & 2,080 & P. verticillata \\
XJA & B. Wang \& H.X. Yin 91-754 & 1991 & Hejing county (XJ) & - & P. verticillata \\
XJBI & No. 1942 & 1978 & Hejing county (XJ) & 2,400 & P. uliginosa \\
XJBI & Qingshuijianmei 87 & 1991 & Urumqi city (XJ) & 2,000 & P. violascens \\
XJU & H. Wang 03052 & 2003 & Nanshan Mountains (XJ) & - & P. leptorhiza \\
XJU & - & - & Heaven Lake of Fukang & & - \\
PE & Zheng 1-046 & 1987 & Urumqi (XJ) & 1,640 & - \\
PE & Xinjiang collection team 1942 & 1978 & Hejing county (XJ) & 2,400 & - \\
PE & Xinjiang collection team 1943 & 1978 & Hejing county (XJ) & 2,400 & - \\
PE & Qingshuijianmei et al. 87 & 1991 & Urumqi city (XJ) & 2,000 & - \\
\hline
\end{tabular}

Note: "-" means that data are not available.

\subsection{Molecular investigation}

A total of 24 Pedicularis samples (11 from field samples and 13 from GenBank) were analyzed (Table 1). The field samples included seven samples of the target Pedicularis and four samples of morphologically similar Pedicularis spp. that tend to cause confusions, i.e. P. anthemifolia (2), P. kansuensis (1) and $P$. verticillata (1). Total genomic DNA was extracted from dried leaves using a modified $4 \times$ CTAB method (Doyle and Doyle, 1987). Polymerase chain reaction (PCR) amplifications and sequencing of matK, $r b c L$ and $t r n H-p s b A$ were performed as described by $\mathrm{Yu}$ et al. (2011). In addition, 39 sequences of the three DNA loci, representing four Pedicularis spp. (P. kansuensis, P. verticillata, P. rupicola and P. glabrescens), were obtained from GenBank (http://www.ncbi.nlm.nih.gov/genbank). Sequences were assembled and edited using Sequencher version 4.1(Gene Codes Corporation, Ann Arbor, MI, USA) and aligned using Geneious version 4.8.2 (Kearse et al., 2012). A combined data matrix of matK, $r b c L$ and $t r n H-p s b A$ was used for analysis. Neighbor joining (NJ) tree (K2P distance model and pairwise deletion) was constructed by MEGA version 6.06 (Tamura et al., 2013) with bootstrap support measured from 1,000 replicates.

\section{Results and discussion}

\subsection{Morphological comparisons}

Based on the standard floras for China and Central Asia (see references above), we identified the target Pedicularis species as P. kansuensis. The morphology of the samples we collected, as well as the herbarium specimens, matched the type material (N. M. Przewalski, s.n., P. verticillata var. chinensis, "China occidentalis, Terra Tangutorum, 28. Juni-8. Juli 1872", available at LE \& K) and the protologue description of the basionym $P$. verticillata var. chinensis and the accepted taxon $P$. kansuensis. It is noteworthy that $P$. kansuensis was not recorded in Xinjiang in the book of "Flora Xinjiangensis" (Pan and Nurbay, 2004). Hence, the closest match in "Flora Xinjiangensis" would be $P$. verticillata. Very likely, the conflicting species identifications in the literature resulted from the use of different taxonomic references. The vegetative characters for distinguishing the two species are the shape of the pinnatifid to pinnatisect radical and cauline leaves, as well as the number and shape of leaf segments (see Table 3 and Fig. 2 for trait differences).

\subsection{Life cycle of the target Pedicularis species}

The root cross sections of the target Pedicularis species did not show any signs of annual growth increments in the form of wider luminar cells arranged in circles or semi-circles (Fig. 3a). This indicates an annual life cycle of the target Pedicularis species. In comparison, perennial species such as $P$. verticillata show distinct, slightly semi-ring porous structures (Fig. 3b). Other annual 
Table 3 Morphological differences between Pedicularis kansuensis and P. verticillata (based on "Flora of China" (Yang et al., 1998))

\begin{tabular}{|c|c|c|}
\hline Trait & P. kansuensis & P. verticillata \\
\hline Life cycle & Annual or biennial & Perennial \\
\hline Leaves & $\begin{array}{l}\text { Pinnatisect with ca. } 10 \text { pairs of segments, these } \\
\text { lanceolate, pinnatipartite, dentate, teeth callose }\end{array}$ & $\begin{array}{l}\text { Pinnatifid to pinnatisect with } 6-10 \text { pairs of } \\
\text { segments, these linear-oblong to } \\
\text { triangular-ovate, incised-dentate, teeth white and } \\
\text { callose }\end{array}$ \\
\hline Inflorescences & Compact to interrupted & Dense \\
\hline Bracts & Leaflike or 3-palmate & Leaflike or 3-palmate \\
\hline Calyces & $\begin{array}{l}\text { Slightly cleft anteriorly, with } 5 \text {, unequal, } \\
\text { triangular lobes }\end{array}$ & $\begin{array}{l}\text { Deeply cleft anteriorly, 3-lobed and grouped } \\
\text { posteriorly }\end{array}$ \\
\hline Corolla color & Purple-pink to purple-red, sometimes white & Purple \\
\hline Capsule shape & Obliquely ovoid & Lanceolate \\
\hline
\end{tabular}

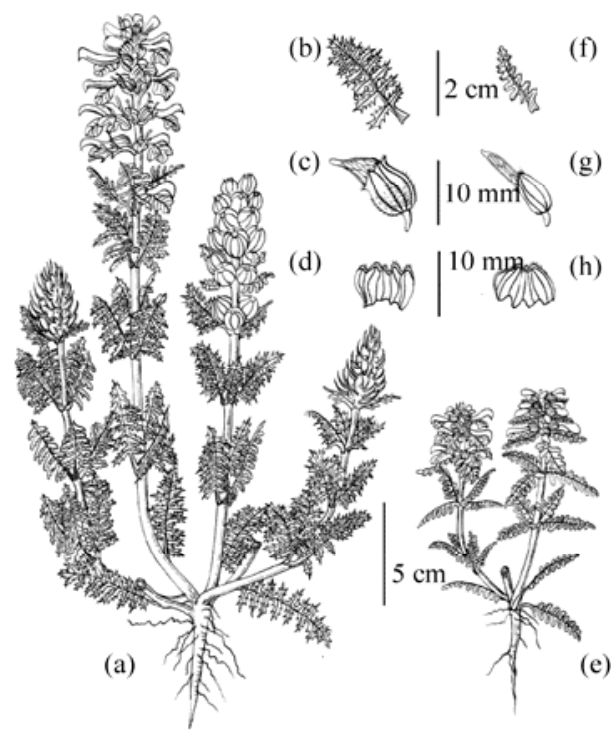

Fig. 2 Illustrations of Pedicularis kansuensis (a-d) and P. verticillata (e-h). (a) and (e), whole plant; (b) and (f), leaves; (c) and (g), fruit; (d) and (h), calyx. Drawn by YIN Genshen based on specimens collected from field.

hemiparasites display a single outer ring often with intra-annual density variation, e.g. Melampyrum spp., Rhinanthus spp. and Odontites spp. (Schweingruber and Poschlod, 2005).

Interestingly, field observations suggested that some individuals of the target species are probably biennial, with rosettes found in late summer that may survive winter and flower in the next summer, then set seeds and die. Obviously the biennial life cycle was not reflected in the growth ring data. We cannot exclude the possibility that annual and biennial plants coexist in the study areas, but this requires further field investigation with carefully identified and labelled individuals throughout their life cycles. Nevertheless, growth ring examination and field observations suggest that the target species is not a perennial.

\subsection{Phylogenetic analyses}

The neighbour-joining tree based on a combined dataset of three chloroplast regions ( $m a t K, r b c L$ and $t r n H-p s b A$ ) is shown in Fig. 4. The 24 samples fell into five distinct clades with high bootstrap support values, indicating these species were well discriminated by the phylogenetic analysis. Field samples from the target Pedicularis species were grouped (at $100 \%$ bootstrap support) with $P$. kansuensis collected from Gansu province as well as those obtained from GenBank. 

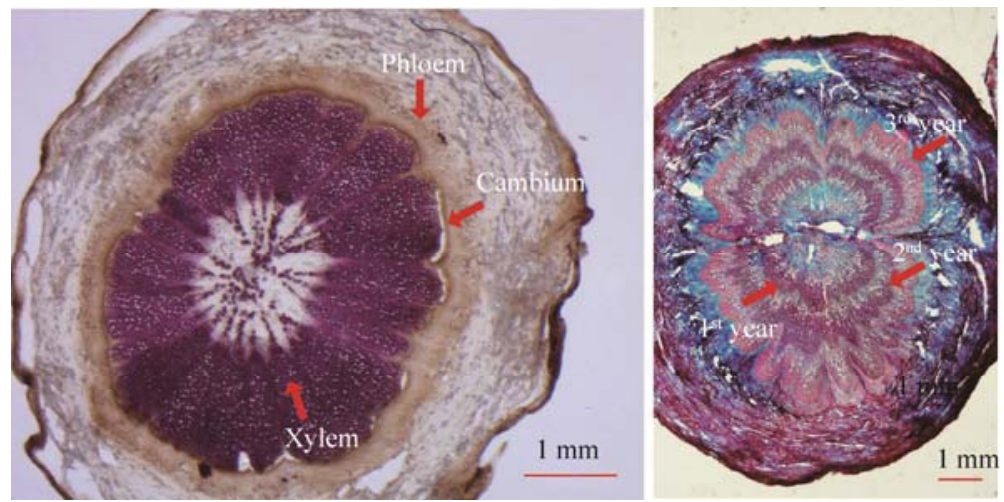

Fig. 3 Root cross-section of the target Pedicularis species (a, single growth ring suggesting an annual life cycle, photographed by SUI Xiaolin) and $P$. verticillata (b, three growth rings suggesting a perennial life cycle, photographed by Dr. Fritz SCHWEINGRUBER, Swiss Federal Research Institute WSL. The image is available at: http://www.wsl.ch/dendropro/xylemdb/index.php?BNAM=Bilder/Scrophulariaceae/Pics/P2022313_mid.jpg\&MO $\mathrm{D}=5$.

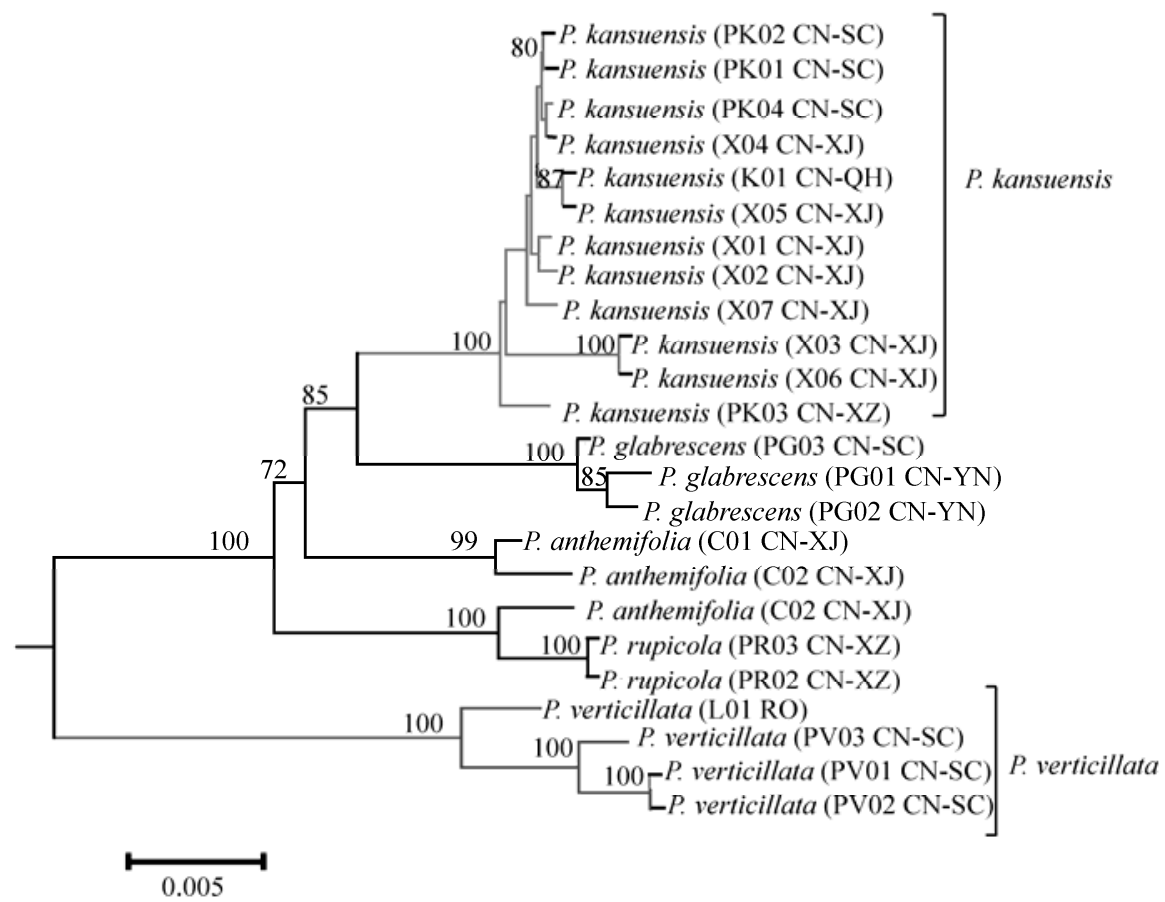

Fig. 4 Neighbour-joining tree based on a combined dataset of three chloroplast regions ( $m a t K$, $r b c L$ and trnH-psbA). Bootstrap values $(>50 \%)$ are shown along respective branches. Code followed by collection locality of each individual was shown in round brackets. For details see Table 1.

\subsection{Distribution}

All verified localities of $P$. kansuensis were distributed in the Tianshan Mountains (Halke range and Borohoro range), Xinjiang (Fig. 5). No specimen or literature data are available for any of other mountain ranges within Xinjiang region, i.e. Altay Mountains and Kunlun Mountains. The overall distribution of $P$. kansuensis is restricted in China (Gansu, Qinghai, Sichuan, Tibet and Yunnan) (Yang et al. 1998) and Nepal (Yamazaki, 1988). It is not recorded in other countries bordering Xinjiang, i.e. India (Husain et al., 2010), Pakistan (Nasir and Ali, 1980), Afghanistan (Breckle and Rafiqpoor, 2010), Tajikistan (Czerepanov, 1995), Kyrgyzstan (Vvedenskii, 1951; Czerepanov, 1995), Kazakhstan (Pavlov, 1965; Czerepanov, 1995), Russia (Vvedenskii, 1951; Czerepanov, 1995; Kosachev, 2010) and Mongolia (Grubov et al., 2002). 


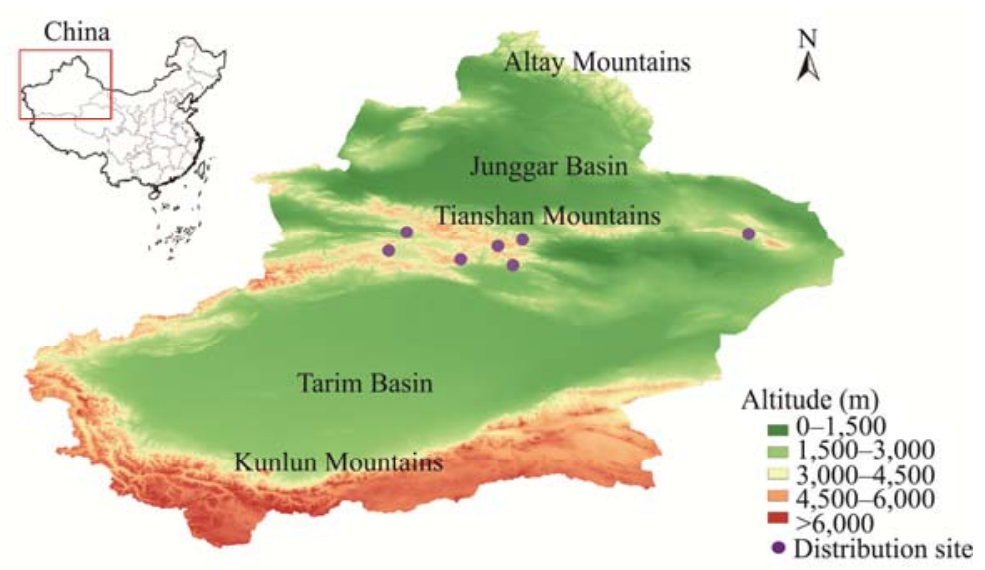

Fig. 5 Distribution map of Pedicularis kansuensis in Xinjiang. Data are from archival materials and field observations.

\section{Conclusions}

Based on morphological, anatomical and genetic data, we found that the identity of the weedy Pedicularis species in Bayanbulak Grassland and surrounding areas is P. kansuensis. Correction of the identification of this Pedicularis species will contribute to a better understanding of the basic biology of this weedy plant (e.g. short life cycle, high fecundity and high seed germination rate, efficient seed dispersal and resistance to disturbance), which provides potential information for effective planning and implementation of control measures against this root hemiparasite.

\section{Acknowledgements}

This work was funded by the National Natural Science Foundation of China (U1303201, 31370512, 31400440), the Youth Innovation Promotion Association of Chines Academy of Sciences, the Stiftung zur Förderung der Pflanzenkenntnis (Basel/CH; Foundation for the Promotion of Plant Knowledge) and the US National Science Foundation (DEB-1119098). We give many thanks to Dr. YU Wenbin and Dr. DONG Hongjin for their suggestions on writing this paper. We thank Professor Sally SMITH and the anonymous reviewers for their valuable comments and suggestions that have greatly improved the paper. We also appreciate help from Dr. BAO Gensheng in providing plant materials and Dr. YIN Genshen for drawing the line illustration.

\section{References}

Ameloot E, Hermy M, Verheyen K. 2006. Rhinanthus: An effective tool in reducing biomass of road verges? An experiment along two motorways. Belgian Journal of Botany, 139(2): 173-187.

Bao G S, Wang H S. 2011. Allelopathic effects of Pedicularis kansuensis Maxim. on several graminaceous grass species on alpine meadow. Chinese Journal of Grassland, 33(2): 88-94. (in Chinese)

Breckle S W, Rafiqpoor M D. 2010. Field Guide Afghanistan: Flora and Vegetation. Bonn: Scientia Bonnensis.

Bullock J M, Pywell R F. 2005. Rhinanthus: a tool for restoring diverse grassland?. Folia Geobotanica, 40(2-3): 273-288.

Cameron D D, White A, Antonovics J. 2009. Parasite-grass-forb interactions and rock-paper-scissor dynamics: predicting the effects of the parasitic plant Rhinanthus minor on host plant communities. Journal of Ecology, 97(6): 1311-1319.

Caswell H. 2001. Matrix Population Models: Construction, Analysis, and Interpretation. Sunderland: Sinauer Associates.

Cissoko M, Boisnard A, Rodenburg J, et al. 2011. New rice for Africa (NERICA) cultivars exhibit different levels of post-attachment resistance against the parasitic weeds Striga hermonthica and Striga asiatica. New Phytologist, 192(4): 952-963.

Czerepanov S K. 1995. Vascular Plants of Russia and Adjacent States (the former USSR). Cambridge: Cambridge University Press.

Davies D M, Graves J D, Elias C O, et al. 1997. The impact of Rhinanthus spp. on sward productivity and composition: Implications for the restoration of species-rich grasslands. Biological Conservation, 82(1): 87-93.

Doyle J J, Doyle J L. 1987. A rapid DNA isolation procedure for small quantities of fresh leaf tissue. Phytochemical Bulletin, 
19: 11-15.

Grubov V I, Ivanina L I, Tscherneva O V. 2002. Plants of Central Asia: Plant Collection from China and Mongolia. vol. 5: Verbenaceae-Scrophulariaceae. Enfield (NH): Science Publishers.

Guan Y P. 2007. Countermeasures of protect and to continued development for the Bayinbuluk Grasslands. Grass-feeding Livestock, (3): 7-9. (in Chinese)

Hautier Y, Hector A, Yojtech E, et al. 2010. Modelling the growth of parasitic plants. Journal of Ecology, 98(4): 857-866.

Husain T, Garg A, Agnihotri P. 2010. Genus Pedicularis L. (Scrophulariaceae) in India: A Revisionary Study. Dehra Dun: Bishen Singh Mahendra Pal Singh.

Irving L J, Cameron D D. 2009. Chapter 3. You are what you eat: interactions between root parasitic plants and their hosts. Advances in Botanical Research, 50: 87-138.

Kearse M, Moir R, Wilson A, et al. 2012. Geneious basic: an integrated and extendable desktop software platform for the organization and analysis of sequence data. Bioinformatics, 28(12): 1647-1649.

Kosachev P A. 2010. Synopsis of the families Scrophulariaceae Juss. and Pediculariaceae Juss. of Altai Mountain Country. Turczaninowia, 13(1): 19-102. (in Russian)

Liu Y Y, Hu Y K, Yu J M, et al. 2008. Study on harmfulness of Pedicularis myriophylla and its control measures. Arid Zone Research, 25(6): 778-782. (in Chinese)

Magda D, Duru M, Theau J P. 2004. Defining management rules for grasslands using weed demographic characteristics. Weed Science, 52(3): 339-345.

Nasir E, Ali S I. 1980. Flora of Pakistan. St. Louis: University of Karachi and Missouri Botanical Press.

Pan X L, Nurbay. 2004. Pedicularis L. In: Flora Xinjiangensis, Vol. 4. Urumqi: Xinjiang Science and Technology Publishing House, 407-422. (in Chinese)

Parker C. 2012. Parasitic weeds: A world challenge. Weed Science, 60(2): 269-276.

Pavlov N V. 1965. Flora Kazachstana, vol. 8. Alma-Ata: Izdatel'stvo Akademii nauk Kazachskoj SSR, 115-145. (in Russian)

Phoenix G K, Press M C. 2005. Linking physiological traits to impacts on community structure and function: the role of root hemiparasitic Orobanchaceae (ex-Scrophulariaceae). Journal of Ecology, 93(1): 67-78.

Schweingruber F H, Poschlod P. 2005. Growth rings in herbs and shrubs: life span, age determination and stem anatomy. Forest Snow and Landscape Research, 79(3): 195-415.

Silvertown J, Charlesworth D. 2001. Introduction to Plant Population Biology (4 ${ }^{\text {th }}$ ed.). Oxford: Blackwell Science.

Song Z S. 2006. It is an urgent task to recovery \& comprehensively manage the grassland ecology of Bayingbuluke. Chinese Journal of Agricultural Resources and Regional Planning, 27(1): 21-25. (in Chinese)

Tamura K, Stecher G, Peterson D, et al. 2013. MEGA6: molecular evolutionary genetics analysis version 6.0. Molecular Biology and Evolution, 30(12): 2725-2729.

Tsoong P C. 1963. Scrophulariaceae (Pars II). In: Tsoong P C. Flora Reipublicae Popularis Sinacae, vol. 68. Beijing: Science Press, 1-449. (in Chinese)

Vvedenskii A I. 1951. Flora of the Kirghiz SSR. Frunze: Academy of Sciences of the Kirghiz SSR. (in Russian)

Wang W X, Sang G J, Li L. 2009. Study on the control techniques of poisons grass Pedicularis in Xinjiang Bayanbulak Prairie. Grass-Feeding Livestock, (2): 49-50. (in Chinese)

Williams A R. 2010. On sustaining the ecology and livestock industry of the Bayanbuluk Grasslands. Journal of Arid Land, 2(1): 57-63.

Yamazaki T. 1988. A revision of the genus Pedicularis in Nepal. In: Ohba H, Malla S B. The Himalayan Plants, Volume 1. Tokyo: The University of Tokyo, Bulletin, 31: 91-161.

Yang H B, Holmgren N H, Mill R R. 1998. Pedicularis L. In: Wu Z Y, Raven P H. Flora of China, vol. 18. Beijing, St. Louis: Science Press Beijing, Missouri Botanical Garden Press, 97-209.

Yu W B, Huang P H, Ree R H, et al. 2011. DNA barcoding of Pedicularis L. (Orobanchaceae): evaluating four universal barcode loci in a large and hemiparasitic genus. Journal of Systematics and Evolution, 49(5): 425-437. 